\title{
Public Debt and the Threat of Secession
}

Max Planck Institute for Tax Law and Public Finance

Working Paper 2015 - 04

June 2015

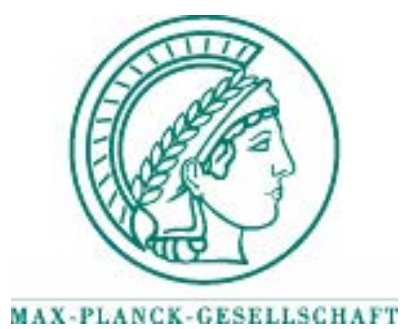

Max Planck Institute for

Tax Law and Public Finance

Department of Business and Tax Law

Department of Public Economics

http:/ /www.tax.mpg.de 
Working papers of the Max Planck Institute for Tax Law and Public Finance Research Paper Series serve to disseminate the research results of work in progress prior to publication to encourage the exchange of ideas and academic debate. Inclusion of a paper in the Research Paper Series does not constitute publication and should not limit publication in any other venue. The preprints published by the Max Planck Institute for Tax Law and Public Finance represent the views of the respective author(s) and not of the Institute as a whole. Copyright remains with the author(s).

Max Planck Institute for Tax Law and Public Finance

Marstallplatz 1

D-80539 Munich

Tel: $\quad+498924246-0$

Fax: $\quad+498924246-501$

E-mail: ssrn@tax.mpg.de

http://www.tax.mpg.de 


\title{
Public Debt and the Threat of Secession
}

\author{
Rhea Molato*
}

May 7, 2015

\begin{abstract}
This paper examines public debt as a strategic instrument in preventing secession. Using a game theoretic model, it shows that debt can be used to preempt a country's separation if the seceding region's potential gain from independence is strictly decreasing in debt. This paper identifies sufficient conditions under which this property holds. First, the indirect effect of debt on the seceding region's potential gain from independence must be negative. Second, the indirect effect of debt must be stronger than its direct effect. When the seceding region's potential gain from independence is decreasing in debt, then it can be prevented from leaving the union by setting higher levels of debt until it reaches a certain threshold level. This paper also finds that the majority region may use debt as a strategic instrument to preserve the union if it is better off in a country with debt than as a separate state with savings.
\end{abstract}

Keywords: secession, debt, sovereign debt, fiscal policy

JEL Classification Codes: H77, H63, H30

${ }^{*}$ Max Planck Institute for Tax Law and Public Finance. Marstallplatz 1, Munich, Germany 80539. Correspondence: rhea.molato@gmail.com. I thank Kai A. Konrad, Florian Morath, Aart Gerritsen, Tim Stolper, Michael Hilmer, Luca Salvadori, Raul Fabella, Matthias Dahm, Trond Olsen, Qiang Fu, Andreas Haufler and participants at the Public Economics Seminar of the Ludwig-Maximilians-University in Munich for helpful comments and suggestions. 


\section{Introduction}

Some countries are dealing with a threat of secession over a long period of time. As these secessionist conflicts remain unresolved, these same countries also carry high levels of public debt. What explains this persistence of unresolved secessionist conflicts alongside large national debt? Could these debt levels possibly explain why actual separation does not occur? This paper applies a game theoretic framework to examine whether public debt plays a strategic role in preventing the breakup of nations.

The idea that public debt has the potential to prevent secession runs counter to the notion that higher debt - and thus lower economic prosperity - is associated with political instability. Truly, many of the countries subject to secessionist threats are characterized with less than stellar economic performance. There is no doubt that instability in the political environment affects economic outcomes adversely and it may well be argued that a bad economic situation can cause political unrest. As one form of political instability, the threat of secession may be driven and fuelled by a country's economic situation. Public debt brings adverse consequences on a country's future economic position. As such, it may be seen as a catalyst for secessionism rather than a potential pacifier. This paper establishes an opposite argument. It delves into the micro foundations behind the possibility of secession and identifies a strategic mechanism through which debt works in the direction of preventing separation rather than facilitating it.

The strategic mechanism identified in this paper works through the effect of debt on the seceding region's potential gain from independence. If the gain from independence is decreasing in debt, then by issuing higher levels of debt the national government in effect sets up stronger constraints on the economic environment that the seceding region will inherit if it eventually becomes an independent state. Once debt reaches a sufficient level, the seceding region will find it more beneficial to stay united with the country than to separate from it.

This mechanism works under a key assumption that per capita burden of 
debt must remain the same whether secession takes place or not. Public debt is a liability which has to be paid back in full regardless of the decision on secession. This simplifying assumption is made because the variable of interest in this paper pertains to the level of debt and not the allocation of debt. It rules out possible instances where secession is motivated by the prospect of lowering a region's share of the debt burden. Rather, it maintains that the prospect of secession is driven by a fundamental reason, difference in preferences.

Essentially, this paper postulates that, given the conditions identified herein, the threat of secession creates a tendency for a country to issue debt in an attempt to stabilize itself. It formalizes one observation, with specific application on debt policy:

"Any state that seeks to avoid its own dissolution would have an incentive to implement policies designed to prevent groups from becoming prosperous enough..." -Allen Buchanan, Theories of Secession

In this theoretical model, I consider a country where two regions differ in terms of preferences for two publicly-provided private goods. With a democratic setup, the majority region in this country is decisive over the level and composition of public spending. The minority region issues a threat of secession in order to obtain independence in making policy choices for its own jurisdiction. I consider the subgame perfect equilibrium and identify conditions under which public debt can be used to preserve the union at the equilibrium outcome.

The central finding in this paper is that public debt can be a strategic instrument in preventing separation if the seceding region's potential gain from independence is decreasing in debt. This potential gain from independence is decreasing in debt if the indirect effect of debt is negative and this indirect effect is stronger than the direct effect of debt. The indirect effect works through the reduction in consumption of the seceding region's less preferred good while the direct effect works through a shift towards this region's preferred good. When the seceding region's potential gain from independence is decreasing in debt, 
the majority region may consider issuing higher levels of debt for the strategic purpose of preventing separation.

The rest of the paper is organized as follows. Section 2 relates this model with the existing literature on debt and secession. Section 3 describes the model and its assumptions. Section 4 considers a benchmark case where the threat of secession is absent. Section 5 analyzes the minority region's decision when there exists a possibility of secession. Section 6 describes the majority region's optimal choice. Section 7 characterizes the equilibrium. The paper ends with a conclusion in Section 8.

\section{Related literature}

The secession decision is usually characterized as a tradeoff between economies of scale and diversity in preferences. This paper focuses on difference in preferences as a motivation behind the option of secession and incorporates the loss in economies of scale into the costs of separation. Alesina and Spolaore (1997) develop a model where an individual's utility is decreasing with the distance between the actual type of government and his "ideal government." They show that there is an excess tendency towards separation. They pointed out that democratization and increasing market integration are both associated with political separatism (also in Alesina, Perotti and Spolaore 1995; Alesina and Spolaore 2005). By removing barriers to trade, economic integration reduces the benefit of scale economies for large countries and opens up a wider market for small countries if they decide to form separate states. ${ }^{1}$

Bolton and Roland (1997) model the secession decision as a tradeoff between the efficiency gains of keeping a union and the benefits of having a redistribution policy closer to the preferences of each region. The motivation to secede is driven by differences in income distribution across regions, which give rise to differences in the preferred tax rate. They show that secession can be prevented

\footnotetext{
${ }^{1}$ Also in Casella 1992; Alesina, Spolaore and Wacziarg 2000; Casella and Feinstein 2002; Ruta 2005.
} 
by setting an accommodating tax rate that is closer to the preferred tax rate of the seceding region than the tax rate set in the absence of such a threat. My model differs from Bolton and Roland in two ways. First, the motivation to secede in this model is driven by difference in preferences without regard to difference in income distribution. Second, it shows that secession can be prevented without the use of accommodating policies.

The existing literature on the prevention of separation carries a general consensus that the majority must adjust national policies towards making them more favorable for the minority group threatening to secede. This policy compromise should be sufficient to keep the minority satisfied, thus preventing them from separating. Le Breton and Weber (2003) demonstrate that secession can be prevented by designing a transfer scheme sufficient to keep the minority region region satisfied if it remains with the union ${ }^{2}$. According to Buchanan and Faith (1987), the mere possibility of separation influences the behaviour of governments towards such a way that they would not otherwise behave in the absence of a secession threat. More specifically, if secession exists as a legal right, it restricts the potential exploitation level of those in office by imposing a limit on their taxation capacity. Their model treats taxation as a form of extraction where the rents are distributed among a "sharing coalition" and are exclusive from the rest of the society. They show that if the citizens outside of this sharing coalition have an option to withdraw from the state, the potential rents become limited.

On a similar note, Anesi (2012) demonstrates how a secessionist threat leads to more favorable policies for the minority group. He uses a model that introduces uncertainty on the economic benefits of integration and the consequences of secession. The majority has information advantage over the minority and this asymmetry of information leads to the inevitability of secession. Anesi shows that secession can be prevented only if the ruling majority pre-commits to minority protection rules. Olofsgard (2003) shows that information asymmetry provides a platform for the electorate to vote for a separatist party through

\footnotetext{
${ }^{2}$ Also in Haimanko et al. 2005.
} 
whom they can extract a larger transfer from the central government.

Anesi and De Donder (2013) identify three general categories of responses to separatist tension - one, a policy compromise to prevent the minority region from seceding; two, fighting separatist movements resulting in violent conflict; three, accepting demands leading to peaceful separation. As in most models, they imply that peaceful prevention of separation involves terms which favor the minority. Radan (2007) documents differences between peaceful secessions and violent secessions and notes that peaceful secessions are usually characterized with the national government's willingness to let go of the secessionist group with minimal or no resistance. If the national government is not willing to let the minority region attain its own independence while the latter insists on separating, it can be predicted that war would ensue.

This paper diverges from the existing literature by describing an instrument in preventing secession which involves neither armed conflict nor compromise. It describes a third alternative using public debt, a burden which has to be carried by both sides. This alternative creates efficiency costs for both the national government and the seceding region but it does not involve resorting to war.

The idea that public debt can be used as a strategic variable to influence the action of future decision makers is well established in other contexts. Tabellini and Alesina (1990) show that there is a tendency to issue debt as a commitment device that shapes future policy towards the direction which current decision makers favor. Their model identifies two countervailing forces - the "level effect" of debt and the "desired composition effect." The "level effect" raises the total level of consumption in the current period while the "desired composition effect" restricts future consumption towards the composition that the current policy maker prefers. If the "desired composition effect" dominates the "level effect," the incumbent is inclined to issue debt in order to tie the hands of its successor. The commitment effect of debt is echoed in similar models by Persson and Svensson (1989) and Alesina and Tabellini (1990). ${ }^{3}$

\footnotetext{
${ }^{3} \mathrm{~A}$ comprehensive literature review on the political economy of budget deficits can be found
} 
The idea in this paper is most similar to the model of Aghion and Bolton (1990) who show that there is a tendency to issue a high level of debt in order for a ruling party to remain in power. Their model introduces an endogenous election outcome and allows for the possibility of debt default. They describe a tendency for the incumbent to create debt as a strategic inefficiency in the sense that it can be used by the ruling party to remain in office yet it carries efficiency costs for the whole country. ${ }^{4}$

In this paper, I describe debt as a strategic inefficiency in the context of secession. A high level of public debt can be issued in order to prevent secession, thus keeping the same decision maker in place. In contrast to Aghion and Bolton, the vote is made on whether one region will separate or stay with the country and not on which political party wins the national elections. If the region decides to secede, the power to make decisions for this region is shifted to another ruler overseeing the new, independent government. If it decides to stay, the national decision maker keeps the authority to choose policies involving this region.

\section{The model}

Consider a two-period model with one country consisting of two regions, $A$ and $B$, whose population sizes are $\eta_{A}$ and $\eta_{B}$, respectively. Without loss of generality, let $\eta_{A}>\eta_{B}$. Region $A$ is referred to as the majority region while region $B$ is considered the minority region. The utility of each citizen is defined over the consumption of two publicly provided private goods, $x$ and $y$. Citizens within each region have homogeneous preferences. The utility of a citizen in region $i$ can be represented as:

$$
U_{i}=\sum_{t=1}^{2}\left[u_{i}\left(x_{t}\right)+v_{i}\left(y_{t}\right)\right], i=A, B
$$

in Alesina and Perotti (1995).

${ }^{4}$ Similar ideas are also described in other models with endogenous election outcomes (Milesi-Ferretti and Spolaore 1994; Milesi-Ferretti 1995). 
where $x_{t}$ and $y_{t}$ are per capita levels of $x$ and $y$, respectively, chosen by the government in period $t=1,2$. The price of each good is normalized to 1 .

Citizens of the two regions have different preferences for $x$ and $y$ in the sense that

$$
\begin{aligned}
& u_{A}^{\prime}\left(x_{t}\right)>u_{B}^{\prime}\left(x_{t}\right), \forall x_{t}>0 \\
& v_{A}^{\prime}\left(y_{t}\right)<v_{B}^{\prime}\left(y_{t}\right), \forall y_{t}>0
\end{aligned}
$$

where $u_{i}^{\prime}\left(x_{t}\right)>0, u_{i}^{\prime \prime}\left(x_{t}\right)<0$ and $v_{i}^{\prime}\left(y_{t}\right)>0, v_{i}^{\prime \prime}\left(y_{t}\right)<0$ for $i=A, B$. In this case, region $\mathrm{A}$ has a stronger preference for good $x$ than region $\mathrm{B}$, while region $\mathrm{B}$ has a stronger preference for good $y$ than region $\mathrm{A}^{5}$

In period 1 , the country is organized as one democractic decision-making unit and under the assumption of majority voting rule, citizens in the majority region are decisive over the levels of consumption, $x_{1}$ and $y_{1}$. The country faces the following budget constraint:

$$
x_{1}+y_{1} \leq 1+d
$$

where per capita output endowment is fixed and normalized to 1 and $d \in[-1, \widehat{d}]$ is the per capita level of public debt that the country can choose to incur in period 1 . This debt will have to be fully repaid in period 2 so $d$ cannot exceed a maximum amount $\widehat{d}=\min \{1-c, 1-k\}$. This model assumes zero discounting and refers to public debt as a small country government's net borrowing from abroad. As such, this external debt cannot affect the world interest rate which is set equal to 0 .

If the country remains united in period 2 , the majority region remains decisive over the level and composition of spending, $x_{2}^{N}$ and $y_{2}^{N}$. The country as a whole will face the following budget constraint in period 2 :

$$
x_{2}^{N}+y_{2}^{N} \leq 1-d
$$

\footnotetext{
${ }^{5}$ The analytical results of this paper are preserved if the difference in preferences is modelled in terms of relative preferences rather than absolute preferences.
} 
If secession takes place, region $\mathrm{B}$ will obtain the right to choose its own levels of consumption in period $2, x_{2}^{B}$ and $y_{2}^{B}$. It will face the following budget constraint as an independent state:

$$
x_{2}^{B}+y_{2}^{B} \leq 1-d-k
$$

where $k \in(0,1)$ represents per capita cost of separation for the minority region. This cost accounts for the fact that a new independent state will have to institute systems necessary for its own governance and the conduct of its own affairs. These systems include but are not limited to the formation of its own national defense, international relations and general administration, among others.

On the other hand, the majority region's citizens will have to choose their own levels of consumption $x_{2}^{A}$ and $y_{2}^{A}$ under the secession scenario. Region A's own budget constraint is given by

$$
x_{2}^{A}+y_{2}^{A} \leq 1-d-c
$$

where $c \in(0,1)$ represents per capita cost of separation for the majority region. This cost pertains to the loss in economies of scale arising from the fact that the fixed costs of running the country will be shared by a fewer number of citizens, resulting to an increase in the burden per capita. ${ }^{6}$

It is crucial to make the neutrality assumption that per capita burden of debt in period 2 remains fixed once it is set in period 1 and each citizen will have to carry the same amount of liability whether secession takes place or the union remains intact. This assumption is necessary in order to keep the allocation of debt burden from contaminating the motivation to secede. It isolates the effect of difference in preferences between the two regions on the possibility of secession. For this reason, it is assumed that the share of debt burden per capita

\footnotetext{
${ }^{6}$ The per capita cost of separation for each region may represent other losses associated with leaving a union. These losses include foregone benefits from a union like interregional transfers (if the region is a net recipient of transfers) and the market size for domestic products (in a world of less than perfect international trade). These losses consist as well of the costs involved in the process of undergoing separation.
} 
is equal to 1 for each citizen in each region under both union and secession. ${ }^{7}$

The model is a dynamic game with complete information and I am interested in the sub-game perfect Nash equilibrium (SPNE) in pure strategies. The sequence of the game is organized as follows and illustrated in Figure 1.

Period 1

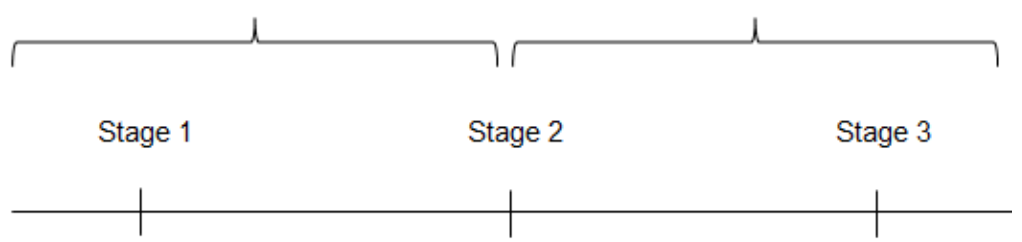

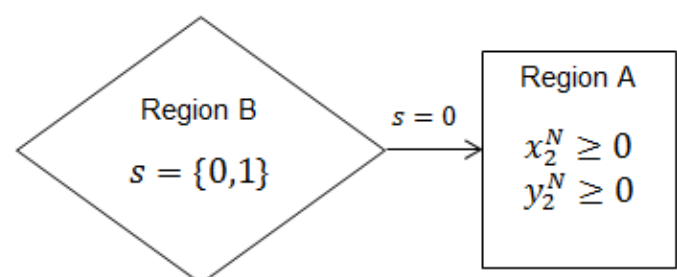

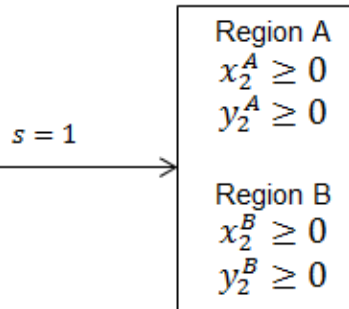

Figure 1. Sequence of the game

In period 1 , region $\mathrm{A}$ chooses per capita consumption levels $\left(x_{1}, y_{1}\right)$ as well as per capita debt level $d \in[-1, \widehat{d]}$ for the whole country. This set of choices comprises stage 1 . Upon observing $\left(x_{1}, y_{1}\right)$ and $d$, region B decides in stage 2 whether it will stay united with the country $\{s=0\}$ or it will secede to form

\footnotetext{
${ }^{7}$ If I relax this assumption and allow the minority region to carry less than its full share of per capita debt burden, the analytical results of this paper continue to hold as long as its share is sufficiently large. Moreover, if the minority region carries per capita debt burden larger than 1 , then in this case the analytical findings of this paper remain intact.
} 
an independent state $\{s=1\}$. If it chooses $s=0$, then at stage 3 region A will choose period 2 consumption levels $\left(x_{2}^{N}, y_{2}^{N}\right)$ subject to (1.5). If, on the other hand, region $\mathrm{B}$ chooses $s=1$, then at stage 3 each region $i \in\{A, B\}$ independently chooses its consumption levels $\left(x_{2}^{i}, y_{2}^{i}\right)$, given the budget constraints (7) and (6), respectively.

The minority region's utility level in period 2 can be described as:

$$
U_{B, 2}=\left\{\begin{array}{l}
u_{B}\left(x_{2}^{N}\right)+v_{B}\left(y_{2}^{N}\right), \text { if } s=0 \\
u_{B}\left(x_{2}^{B}\right)+v_{B}\left(y_{2}^{B}\right), \text { if } s=1
\end{array}\right\} .
$$

The majority region's utility in the last period is given by:

$$
U_{A, 2}=\left\{\begin{array}{l}
u_{A}\left(x_{2}^{N}\right)+v_{A}\left(y_{2}^{N}\right), \text { if } s=0 \\
u_{A}\left(x_{2}^{A}\right)+v_{A}\left(y_{2}^{A}\right), \text { if } s=1
\end{array}\right\} .
$$

Finally, I assume the tie-breaking rule that region $\mathrm{B}$ chooses $s=0$ (the union) if its period 2 utility levels under both scenarios are exactly the same. ${ }^{8}$

\section{Equilibrium without threat of secession}

Consider a benchmark case where there is no threat of secession. For this case, region A will choose the optimal consumption levels $\left(x_{1}^{* N}, y_{1}^{* N}\right)$ for period 1 and $\left(x_{2}^{* N}, y_{2}^{* N}\right)$ for period 2 that maximize its total utility (1) subject to the budget constraints (4) and (5). Its total payoff is given by

$$
U_{A}^{N}=u_{A}\left(x_{1}^{* N}\right)+v_{A}\left(y_{1}^{* N}\right)+u_{A}\left(x_{2}^{* N}\right)+v_{A}\left(y_{2}^{* N}\right) .
$$

\footnotetext{
${ }^{8}$ In order to focus on the effect of debt as a strategic instrument in preventing secession, this model also assumes that the majority region cannot credibly commit to other forms of preemptive mechanisms such as interregional transfers and accommodating policies for the minority region. These are instruments already described in the existing literature on secession.
} 
The optimal consumption levels must satisfy the following first-order condition (FOC):

$$
u_{A}^{\prime}\left(x_{1}^{* N}\right)=v_{A}^{\prime}\left(y_{1}^{* N}\right)=u_{A}^{\prime}\left(x_{2}^{* N}\right)=v_{A}^{\prime}\left(y_{2}^{* N}\right),
$$

which, in line with the consumption smoothing argument by Barro (1979), implies that

$$
\begin{gathered}
x_{1}^{* N}=x_{2}^{* N} \\
y_{1}^{* N}=y_{2}^{* N} \Rightarrow 1+d^{*}-x_{1}^{* N}=1-d^{*}-x_{2}^{* N} .
\end{gathered}
$$

This can be satisfied if and only if

$$
d^{*}=0
$$

Thus, at the equilibrium where there is no threat of secession, the optimal level of debt is equal to zero.

\section{Equilibrium with threat of secession}

Consider now the game with a threat of secession. To express region B's motivation to entertain the possibility of seceding, this game assumes that at $d=0$, region B's period 2 utility level under secession is higher than its period 2 utility level under the union:

$$
U_{B, 2}(s=1, d=0)>U_{B, 2}(s=0, d=0) .
$$

To see whether issuing a specific amount of debt can influence the minority region's decision on secession, I solve the game by backward induction. At stage 3 , the subgame depends on whether region B chooses $s=0$ or $s=1$ in stage 2 .

If $s=0$, the subgame at stage 3 is characterized by public provision of private goods at levels $x_{2}^{* N}$ and $y_{2}^{* N}$ which maximize region A's period 2 utility

$$
U_{A, 2}^{N}=u_{A}\left(x_{2}^{N}\right)+v_{A}\left(y_{2}^{N}\right)
$$


subject to

$$
x_{2}^{N}+y_{2}^{N} \leq 1-d
$$

for any given debt level $d$ chosen in stage 1 of the game. Using that

$$
y_{2}^{* N}=1-d-x_{2}^{* N},
$$

the consumption levels $\left(x_{2}^{* N}, y_{2}^{* N}\right)$ satisfy the following FOC:

$$
u_{A}^{\prime}\left(x_{2}^{* N}\right)=v_{A}^{\prime}\left(1-d-x_{2}^{* N}\right)
$$

Thus, region B's payoff in this outcome at stage 3 is given by

$$
U_{B, 2}(s=0, d)=u_{B}\left(x_{2}^{* N}\right)+v_{B}\left(1-d-x_{2}^{* N}\right),
$$

for any given level of debt $d$.

If $s=1$, the subgame at stage 3 for region $\mathrm{B}$ is characterized by public provision of private goods at levels $x_{2}^{* B}$ and $y_{2}^{* B}$ which maximize region B's period 2 utility

$$
U_{B, 2}^{S}=u_{B}\left(x_{2}^{B}\right)+v_{B}\left(y_{2}^{B}\right)
$$

subject to the minority region's budget constraint,

$$
x_{2}^{B}+y_{2}^{B} \leq 1-d-k,
$$

for any given level of debt $d$ set by region $\mathrm{A}$ in period 1. Using that

$$
y_{2}^{* B}=1-d-k-x_{2}^{* B}
$$

the consumption levels $\left(x_{2}^{* B}, y_{2}^{* B}\right)$ satisfy the following FOC:

$$
u_{B}^{\prime}\left(x_{2}^{* B}\right)=v_{B}^{\prime}\left(1-d-k-x_{2}^{* B}\right) .
$$


Thus, region B's payoff in this outcome at stage 3 is given by

$$
U_{B, 2}(s=1, d)=u_{B}\left(x_{2}^{* B}\right)+v_{B}\left(1-d-k-x_{2}^{* B}\right),
$$

for any given level of debt $d$.

At stage 2, region B's option $s=1$ dominates $s=0$ if and only if

$$
U_{B, 2}(s=1, d)>U_{B, 2}(s=0, d) .
$$

As a result of the assumptions on preferences represented in (2) and (3), the optimal bundles of consumption in the two subgames differ in such a way that region $\mathrm{B}$ will always choose a lower consumption of $x_{2}$ if it decides to secede,

$$
x_{2}^{* N}>x_{2}^{* B},
$$

while there are two possible directions for $y_{2}$. On one hand, region B prefers a higher consumption of $y_{2}$ compared to region A. On the other hand, the cost of secession $k$ entails that region B's consumption of $y_{2}$ as an independent state may be lower than its consumption in a union. The first possibility dominates the second possibility, that is,

$$
y_{2}^{* B}>y_{2}^{* N},
$$

if and only if $k$ is sufficiently small:

$$
k<x_{2}^{* N}-x_{2}^{* B}
$$

One necessary condition for region B to consider a threat of secession is for (13) to be satisfied. Thus, the possibility of secession is a credible threat only if (b) holds. 


\subsection{The relationship between debt and preference mis- match}

In a united situation, the majority region imposes its preferences on the minority region and allocates per capita income on the two publicly-provided private goods while applying its own consumption preferences. This implies that citizens in the minority region cannot make the best use of their income and, for a given income level, they suffer a utility loss compared to the optimal use of this income. In this section, I study how this utility loss changes with a change in per capita debt level, which is effectively a unit reduction in income. I provide sufficient conditions that establish a monotonic relationship between the size of per capita debt and this utility loss. In order to establish this I need the following notation:

Definition 1 Let $\Delta \equiv U_{B, 2}(s=1, d)-U_{B, 2}(s=0, d)$ be defined as region $B$ 's potential "gain from independence" or, equivalently, region B's utility loss associated with staying in the union, for any given level of debt $d$.

Region B optimally chooses $s=1$ in stage 2 if $\Delta>0$ and $s=0$ if $\Delta \leq 0$. Let us then examine the sensitivity of $\Delta$ with respect to public debt $d$. Substituting (9) and (11) into Definition 1, $\Delta$ can be expressed in terms of $d$ as:

$$
\Delta=u_{B}\left(x_{2}^{* B}\right)+v_{B}\left(1-d-k-x_{2}^{* B}\right)-u_{B}\left(x_{2}^{* N}\right)-v_{B}\left(1-d-x_{2}^{* N}\right) .
$$

Assumption 1. $\Delta$ is monotonically declining in $d$.

With Assumption 1, I consider the minority region's decision in stage 2 on whether to separate or not. This decision can be charaterized as follows.

Proposition 1 Suppose (a) holds and Assumption 1 is satisfied. Then there exists a unique threshold debt level $\bar{d} \in(0,1-k)$ such that region B's optimal choice at stage 2 is $s^{*}=0$ if and only if $d \geq \bar{d}$.

Proof. First note that $\Delta$ is continuous in $d$ everywhere, by the continuity of $u_{i}\left(x_{t}\right)$ and $v_{i}\left(y_{t}\right)$. At $d=0, \Delta>0$ if $(a)$ holds. At $d=1-k, \Delta<0$ since 
$x_{2}^{* B}=0$ and $y_{2}^{* B}=0$ for $s=0$ while $x_{2}^{* N} \geq 0$ and $y_{2}^{* N} \geq 0$ with at least one equation being a strict inequality for $s=1$. The assumptions $u_{i}^{\prime}\left(x_{t}\right)>0$ and $v_{i}^{\prime}\left(y_{t}\right)>0$ ensure that $U_{B, 2}(s=1, d=1-k)=u_{B}(0)+v_{B}(0)<U_{B, 2}(s=$ $0, d=1-k)=u_{B}\left(x_{2}^{* N}\right)+v_{B}\left(y_{2}^{* N}\right)$. By Assumption $1, \Delta$ is monotonically declining in $d$. Hence, by the Intermediate Value Theorem, there exists a unique $\bar{d} \in(0,1-k)$ satisfying $\Delta(\bar{d})=0$.

Region B's decision whether to stay together with region A or to separate follows a threshold rule. There is exactly one level of debt $\bar{d}$ that makes region B indifferent about whether to secede or not. For levels of debt exceeding this threshold, region B prefers to stay in the union, and for levels of debt below this threshold, region B prefers to separate. This condition determines the nonseparation constraint (NSC), by which region B chooses $s^{*}=0$ in stage 2 if region A sets debt level $d$ in stage 1 such that

$$
d \geq \bar{d}
$$

Figure 2 illustrates that if the potential gain from independence is monotonically decreasing in debt, region B will always prefer to stay in the union once debt crosses the threshold level $\bar{d}$. 


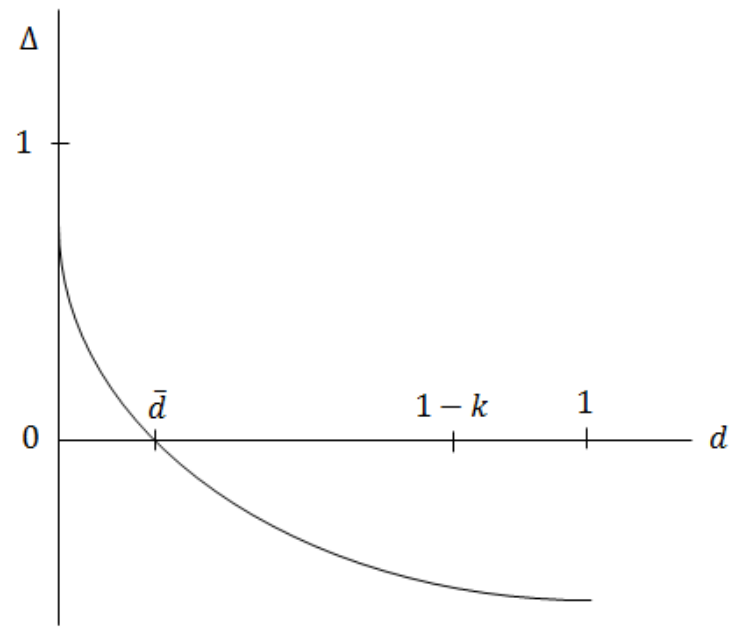

Figure 2. Potential gain from independence as a function of the debt level

Let $U_{A}=\sum_{t=1,2}\left[\beta \sqrt{x_{t}}+\sqrt{y_{t}}\right]$ and $U_{B}=\sum_{t=1,2}\left[\sqrt{x_{t}}+\gamma \sqrt{y_{t}}\right]$, where $\beta, \gamma>1$. This example satisfies the model assumptions in (2) and (3). If the country remains united in period 2, the consumption levels of $x$ and $y$ that region A will choose for the country are given by

$$
x_{2}^{* N}=\frac{\beta^{2}}{\beta^{2}+1}(1-d), \quad y_{2}^{* N}=\frac{1}{\beta^{2}+1}(1-d) .
$$

On the other hand, if region B decides to secede, its period 2 consumption levels will be equal to

$$
x_{2}^{* B}=\frac{1}{\gamma^{2}+1}(1-d-k), y_{2}^{* B}=\frac{\gamma^{2}}{\gamma^{2}+1}(1-d-k) .
$$

The direct effect of debt on $\Delta$ is equal to

$$
\frac{1}{2}\left(\frac{\gamma \sqrt{\beta^{2}+1}}{\sqrt{1-d}}-\frac{\sqrt{\gamma^{2}+1}}{\sqrt{1-d-k}}\right)
$$


while the indirect effect is given by

$$
-\frac{\beta^{2}}{\beta^{2}+1}\left[\frac{1}{2}\left(\gamma-\frac{1}{\beta}\right) \sqrt{\frac{\beta^{2}+1}{1-d}}\right],
$$

which is negative if $\gamma>\frac{1}{\beta}$. The total effect of debt on $\Delta$ is negative if

$$
\frac{(\beta+\gamma)^{2}}{\left(\gamma^{2}+1\right)\left(\beta^{2}+1\right)}<\frac{1-d}{1-d-k}
$$

a condition that is always satisfied given that $\beta, \gamma>1$ and $k>0$. Thus, in this example, region B's potential gain from independence is monotonically decreasing in debt. By Proposition 1, there exists a unique threshold level of debt $\bar{d}$ such that region $\mathrm{B}$ will choose to stay in the union if region $\mathrm{A}$ sets the public debt level $d \geq \bar{d}$. This threshold level $\bar{d}$ is given by

$$
\bar{d}=1-M k
$$

where

$$
M \equiv \frac{\left(1+\gamma^{2}\right)^{2}\left(\beta^{2}+1\right)}{\left(1+\gamma^{2}\right)^{2}\left(\beta^{2}+1\right)-(\beta+\gamma)^{2}\left(\gamma^{2}+1\right)} .
$$

Figure 2 illustrates the relationship between $\Delta$ and the levels of public debt $d$ if the conditions in Lemma 1 are satisfied. When the potential gain from independence is monotonically decreasing in debt, region B will always prefer to stay in the union once debt crosses the threshold level $\bar{d}$.

\subsection{An example}

With the following example, I show that Assumption 1 is satisfied and illustrate that there exists a threshold level of debt $\bar{d}$ which can be used to prevent the minority region from seceding.

Let $U_{A}=\sum_{t=1,2}\left[\beta \sqrt{x_{t}}+\sqrt{y_{t}}\right]$ and $U_{B}=\sum_{t=1,2}\left[\sqrt{x_{t}}+\gamma \sqrt{y_{t}}\right]$, where $\beta, \gamma>1$. This example satisfies the model assumptions in (2) and (3). If the country remains united in period 2, the consumption levels of $x$ and $y$ that 
region A will choose for the country are given by

$$
x_{2}^{* N}=\frac{\beta^{2}}{\beta^{2}+1}(1-d), \quad y_{2}^{* N}=\frac{1}{\beta^{2}+1}(1-d) .
$$

On the other hand, if region B decides to secede, its period 2 consumption levels will be equal to

$$
x_{2}^{* B}=\frac{1}{\gamma^{2}+1}(1-d-k), y_{2}^{* B}=\frac{\gamma^{2}}{\gamma^{2}+1}(1-d-k) .
$$

Region B's potential gain from independence is given by

$$
\Delta=\sqrt{\frac{1}{\gamma^{2}+1}(1-d-k)}+\gamma \sqrt{\frac{\gamma^{2}}{\gamma^{2}+1}(1-d-k)}-\sqrt{\frac{\beta^{2}}{\beta^{2}+1}(1-d)}-\gamma \sqrt{\frac{1}{\beta^{2}+1}(1-d)} .
$$

The effect of debt on $\Delta, \frac{d \Delta}{d d}$, is strictly negative if

$$
\frac{(\beta+\gamma)^{2}}{\left(\gamma^{2}+1\right)\left(\beta^{2}+1\right)}<\frac{1-d}{1-d-k}
$$

a condition that is always satisfied given that $\beta, \gamma>1$ and $k>0$. Thus, in this example, region B's potential gain from independence is monotonically decreasing in debt. By Proposition 1, there exists a unique threshold level of debt $\bar{d}$ such that region $\mathrm{B}$ will choose to stay in the union if region $\mathrm{A}$ sets the public debt level $d \geq \bar{d}$. This threshold level $\bar{d}$ is given by

$$
\bar{d}=1-M k
$$

where

$$
M \equiv \frac{\left(\gamma^{2}+1\right)\left(\beta^{2}+1\right)}{\left(\gamma^{2}+1\right)\left(\beta^{2}+1\right)-(\beta+\gamma)^{2}} .
$$




\section{The decision of the majority region}

In this section, I examine the majority region's equilibrium choice of public debt. Using backward induction, I first describe region A's total payoff at the end of the game for any given level of debt $d$ that it sets in period 1 .

Region A enters one of two possible subgames at stage 3. If region B chooses $s=0$ at stage 2 , then region A enters the non-secession subgame at stage 3 . In this subgame, region A chooses the consumption levels for periods 1 and 2 that maximize its total utility (1) subject to the budget constraints (4) and (5) and the non-separation constraint in $(c)$. Let $\lambda$ be the Lagrange multiplier for the inequality constraint $(c)$. This constraint is binding so $\lambda>0$ and the optimal consumption levels $\left(\bar{x}_{1}^{* N}, \bar{y}_{1}^{* N}, \bar{x}_{2}^{* N}, \bar{y}_{2}^{* N},\right)$ satisfy the FOCs:

$$
u_{A}^{\prime}\left(\bar{x}_{1}^{* N}\right)=v_{A}^{\prime}\left(\bar{y}_{1}^{* N}\right)=u_{A}^{\prime}\left(\bar{x}_{2}^{* N}\right)-\lambda=v_{A}^{\prime}\left(\bar{y}_{2}^{* N}\right)-\lambda
$$

and

$$
d=\bar{d}
$$

These conditions are satisfied simultaneously by the optimal choice of debt,

$$
d^{* N}=\bar{d}
$$

Thus, region A's total payoff in this subgame is equal to

$$
U_{A}^{*}\left(s=0, d^{* N}=\bar{d}\right)=u_{A}\left(\bar{x}_{1}^{* N}\right)+v_{A}\left(\bar{y}_{1}^{* N}\right)+u_{A}\left(\bar{x}_{2}^{* N}\right)+v_{A}\left(\bar{y}_{2}^{* N}\right) .
$$

If region $\mathrm{B}$ chooses $s=1$ at stage 2 , then region $\mathrm{A}$ enters the secession subgame at stage 3 . In this subgame, region A chooses the consumption levels for periods 1 and 2 that maximize its total utility (1) subject to budget constraints (4) and (7). The optimal consumption levels $\left(x_{1}^{* S}, y_{1}^{* S}, x_{2}^{* A}, y_{2}^{* A}\right)$ satisfy the FOC:

$$
u_{A}^{\prime}\left(x_{1}^{* S}\right)=v_{A}^{\prime}\left(y_{1}^{* S}\right)=u_{A}^{\prime}\left(x_{2}^{* A}\right)=v_{A}^{\prime}\left(y_{2}^{* A}\right) .
$$


Thus,

$$
\begin{gathered}
x_{1}^{* S}=x_{2}^{* A} \\
y_{1}^{* S}=y_{2}^{* A} \Rightarrow 1+d-x_{1}^{* S}=1-d-c-x_{2}^{* A} .
\end{gathered}
$$

Region A's optimal choice of debt in this subgame is

$$
d^{* S}=-\frac{c}{2}
$$

Region A should save in period 1 in order to smooth its consumption over the two periods. Its total payoff in this subgame is

$$
U_{A}^{*}\left(s=1, d^{* S}=-\frac{c}{2}\right)=u_{A}\left(x_{1}^{* S}\right)+v_{A}\left(y_{1}^{* S}\right)+u_{A}\left(x_{2}^{* A}\right)+v_{A}\left(y_{2}^{* A}\right) .
$$

The subgame perfect Nash equilibrium of this game depends on whether

$$
U_{A}^{*}\left(s=0, d^{* N}=\bar{d}\right) \geq U_{A}^{*}\left(s=1, d^{* S}=-\frac{c}{2}\right)
$$

or not.

\section{The optimal debt and secession decisions}

Taking together the optimal decisions of regions A and B at each stage of the game, I now characterize the subgame perfect Nash equilibrium. I show that this game has one unique equilibrium. This equilibrium can be one of two types: one where region A issues a specific level of debt sufficient to keep region B from separating and another where region A chooses to keep savings in period 1 and region $\mathrm{B}$ decides to secede at stage 2 . When conditions that support the first type of equilibrium are fulfilled, public debt acts as a strategic instrument in preserving the union. Otherwise, secession occurs.

Proposition 2 Suppose $\frac{d \Delta}{d d}<0$. If (e) holds, then in the subgame perfect equilibrium region $A$ sets $d^{*}=\bar{d}$ and region $B$ optimally chooses $s^{*}=0$. Otherwise, if 
(e) does not hold, then in the subgame perfect equilibrium region $A$ sets $d^{*}=-\frac{c}{2}$ and region $B$ optimally chooses $s^{*}=1$.

Proof. By backward induction, region A sets $d^{*}=\bar{d}$ at stage 1 if and only if (e) holds. By Proposition 1, region B chooses $s^{*}=0$ at stage 2 if $d \geq \bar{d}$, given $\frac{d \Delta}{d d}<0$. On the other hand, if $(e)$ does not hold, then by backward induction, region A sets $d^{*}=-\frac{c}{2}$ at stage 1 . Because $d^{*}=-\frac{c}{2}$ does not satisfy the nonseparation constraint expressed in $(c)$, then at stage 2 region B chooses $s^{*}=1$.

Proposition 2 implies that, for the union to be preserved using public debt, region A must be better off in a union with debt $\bar{d}$ than as a separate state with savings equal to half of its own separation cost.

To illustrate the tradeoff in (e), I revisit the parametrization of utility in the previous example and characterize the equilibrium as follows.

\subsection{Example}

Given $U_{A}=\sum_{t=1,2}\left[\beta \sqrt{x_{t}}+\sqrt{y_{t}}\right]$, region A has the option to set $d^{* N}=\bar{d}$ and obtain consumption levels in periods 1 and 2 equal to

$$
\begin{aligned}
& \bar{x}_{1}^{* N}=\frac{\beta^{2}}{1+\beta^{2}}+\frac{\beta^{2}}{1+\beta^{2}} \cdot \bar{d}, \quad \bar{y}_{1}^{* N}=\frac{1}{1+\beta^{2}}+\frac{1}{1+\beta^{2}} \cdot \bar{d} \\
& \bar{x}_{2}^{* N}=\frac{\beta^{2}}{1+\beta^{2}}-\frac{\beta^{2}}{1+\beta^{2}} \cdot \bar{d}, \quad \bar{y}_{2}^{* N}=\frac{1}{1+\beta^{2}}-\frac{1}{1+\beta^{2}} \cdot \bar{d} .
\end{aligned}
$$

In this case, region A will end up with total payoff

$$
U_{A}^{*}\left(s=0, d^{* N}=\bar{d}\right)=\beta \sqrt{\bar{x}_{1}^{* N}}+\sqrt{\bar{y}_{1}^{* N}}+\beta \sqrt{\bar{x}_{2}^{* N}}+\sqrt{\bar{y}_{2}^{* N}}
$$

On the other hand, if region A sets $d^{* S}=-\frac{c}{2}$, its optimal consumption bundle for periods 1 and 2 is given by

$$
x_{1}^{* S}=\frac{\beta^{2}}{1+\beta^{2}}-\frac{\beta^{2}}{2+2 \beta^{2}} \cdot c, \quad y_{1}^{* S}=\frac{1}{1+\beta^{2}}-\frac{1}{2+2 \beta^{2}} \cdot c
$$




$$
x_{2}^{* A}=\frac{\beta^{2}}{1+\beta^{2}}+\frac{\beta^{2}}{2+2 \beta^{2}} \cdot c, \quad y_{2}^{* A}=\frac{1}{1+\beta^{2}}+\frac{1}{2+2 \beta^{2}} \cdot c
$$

Its total payoff by the end of this game is characterized as:

$$
U_{A}^{* S}\left(s=1, d^{* S}=-\frac{c}{2}\right)=\beta \sqrt{x_{1}^{* S}}+\sqrt{y_{1}^{* S}}+\beta \sqrt{x_{2}^{* A}}+\sqrt{y_{2}^{* A}}
$$

Region A will optimally choose to preempt secession using debt if (e) holds. Plugging in the payoffs (19) and (20) into (e), I find that in this example, region A will optimally choose to preserve the union as long as the threshold debt level is sufficiently small:

$$
\bar{d} \leq \frac{c}{2}
$$

With the threshold debt level $\bar{d}$ given by (15), region A uses debt in equilibrium if and only if

$$
c \geq 2-2 M k
$$

Figure 3 illustrates the equilibrium in this example for given costs of separation, $c$ and $k$. In this figure, $\bar{k}=x_{2}^{* N}-x_{2}^{* B}$ represents the dividing line between a credible threat of secession and the benchmark case where there is no threat of secession. 


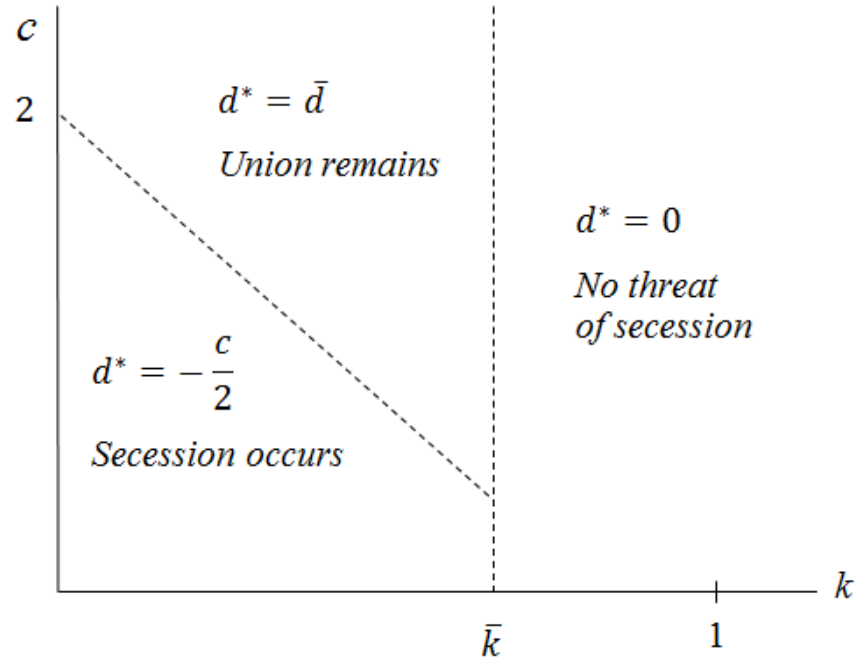

Figure 3. Equilibrium at given levels of separation costs,

$c$ and $k$

\subsection{Comparative statics}

Consider an increase in $c$ holding all other variables fixed. Region A's utility as a separate state with savings shifts downwards, i.e., $U_{A}^{*}\left(s=1, d^{* S}=-\frac{c}{2}\right)$ is smaller, if $c$ is higher. The right-hand side of $(e)$ decreases if $c$ increases. Thus, a subgame perfect equilibrium in which the union is preserved using public debt $\left(s^{*}=0, d^{*}=\bar{d}\right)$ is supported by high costs of separation for region A.

Now consider the effect of a marginal change in $k$, holding all other variables fixed. Region B's cost of separation $k$ affects the subgame perfect equilibrium through its effect on the threshold debt level $\bar{d}$. Region A's utility under the union is (weakly) decreasing in $\bar{d}$ because if a higher threshold level of debt is needed to prevent secession, the intertemporal distortion arising from consumption unsmoothing will also be higher. The left-hand side of $(e)$ weakly decreases as $\bar{d}$ increases. Region B's cost of separation $k$ in turn affects $\bar{d}$ in a less straightforward manner. As $k$ increases, the associated $\bar{d}$ is lower if $v_{B}^{\prime \prime \prime}\left(y_{t}\right)>0$. On the other hand, $\bar{d}$ is increasing in $k$ if $v_{B}^{\prime \prime \prime}\left(y_{t}\right)<0$. Thus, the overall effect of $k$ on 
the union's preservation depends on whether $v_{B}^{\prime \prime}\left(y_{t}\right)$ is increasing or decreasing in $y_{t}$. If $v_{B}^{\prime \prime}\left(y_{t}\right)$ is increasing, then a higher $k$ supports a subgame perfect equilibrium where the union is saved using debt as a strategic instrument. If $v_{B}^{\prime \prime}\left(y_{t}\right)$ is decreasing, then a higher $k$ is associated with a subgame perfect equilibrium where secession takes place.

\section{Conclusion}

This paper demonstrates that public debt can be used as a strategic instrument in preventing secession. This argument differs from the notion that a high level of government debt intensifies the possibility of separation and adds to political instability in general. While this paper does not discount this notion, it establishes that there is a strategic mechanism through which the effect of debt acts in the direction of preserving a country's unity.

This counter-intuitive argument is brought forth by identifying micro foundations behind the decision on secession. It recognizes difference in preferences as the fundamental basis behind a minority region's possibility of calling for independence. The potential gain from independence that this region can achieve through secession arises from utility gains in choosing consumption bundles according to its own preference. This paper shows that this potential gain from independence may be affected by debt. On one hand, debt has a positive direct effect through the minority region's preferred good. On the other hand, debt can have a negative indirect effect through this region's less preferred good. If the indirect effect is negative and stronger than the direct effect, then the potential gain from independence is strictly decreasing in debt.

The property of decreasing gain from independence is central in this argument. If this property holds, then by raising the debt level the national government can influence the minority region's decision on secession because higher debt levels leave the seceding region with lesser gains from leaving the union. This paper proves that the debt level can be set high enough to induce the minority region to stay in the union. 
Given that the gain from independence is decreasing in debt, it is in the best interest of the majority region to set public debt at a strategically high level and thus preempt secession if it finds itself better off in a united country carrying this debt than as a separate state with some savings. This is more likely the case if its own cost of separation is high.

The issuance of public debt for the purpose of preventing secession makes it a strategic inefficiency. It is inefficient in the sense that it distorts the intertemporal path of public spending and creates efficiency costs in doing so. Nonetheless, it is strategic in the sense that it can influence the secession outcome towards preserving a country's unity. The findings of this paper imply that the very existence of a secession threat may create a tendency for the country to set an inefficiently high level of debt for the strategic purpose of keeping itself intact. 


\section{References}

[1] Aghion, P., \& Bolton, P. (1990). Government domestic debt and the risk of default: a political-economic model of the strategic role of debt. Public debt management: theory and history, 315 .

[2] Alesina, A., \& Perotti, R. (1995). The Political Economy of Budget Deficits. IMF Staff Papers, 42(1), 1-31.

[3] Alesina, A., Perotti, R., \& Spolaore, E. (1995). Together or separately? Issues on the costs and benefits of political and fiscal unions. European Economic Review, 39(3), 751-758.

[4] Alesina, A., \& Spolaore, E. (1997). On the number and size of nations. The Quarterly Journal of Economics, 112(4), 1027-1056.

[5] Alesina, A., \& Spolaore, E. (2005). War, peace, and the size of countries. Journal of Public Economics, 89(7), 1333-1354.

[6] Alesina, A., Spolaore, E., \& Wacziarg, R. (2000). Economic Integration and Political Disintegration. The American Economic Review, 90(5), 12761296.

[7] Alesina, A., \& Tabellini, G. (1990). A positive theory of fiscal deficits and government debt. The Review of Economic Studies, 57(3), 403-414.

[8] Anesi, V. (2012). Secessionism and minority protection in an uncertain world.Journal of Public Economics, 96(1), 53-61.

[9] Anesi, V., \& De Donder, P. (2013). Voting under the threat of secession: accommodation versus repression. Social Choice and Welfare, 1-21.

[10] Barro, R. J. (1979). On the determination of the public debt. The Journal of Political Economy, 940-971.

[11] Bolton, P., \& Roland, G. (1997). The breakup of nations: a political economy analysis. The Quarterly Journal of Economics, 112(4), 1057-1090. 
[12] Buchanan, A. (1997). Theories of secession. Philosophy $\&$ public affairs, 26(1), 31-61.

[13] Buchanan, J. M., \& Faith, R. L. (1987). Secession and the limits of taxation: Toward a theory of internal exit. The American Economic Review, 77(5), 1023-1031.

[14] Casella, A. (1992). On markets and clubs: economic and political integration of regions with unequal productivity. The American Economic Review, 82(2), 115-121.

[15] Casella, A., \& Feinstein, J. S. (2002). Public goods in trade: on the formation of markets and jurisdictions. International Economic Review, 437-462.

[16] Debreu, G., \& Koopmans, T. C. (1982). Additively decomposed quasiconvex functions. Mathematical Programming, 24(1), 1-38.

[17] Haimanko, O., Le Breton, M., \& Weber, S. (2005). Transfers in a polarized country: bridging the gap between efficiency and stability. Journal of Public Economics, 89(7), 1277-1303.

[18] Le Breton, M., \& Weber, S. (2003). The art of making everybody happy: how to prevent a secession. IMF Staff Papers, 403-435.

[19] Milesi-Ferretti, G. M. (1995). DO GOOD OR DO WELL? PUBLIC DEBT MANAGEMENT IN A TWO-PARTY ECONOMY*. Economics $\& 3$ Politics, 7(1), 59-78.

[20] Milesi-Ferretti, G. M., \& Spolaore, E. (1994). How cynical can an incumbent be? Strategic policy in a model of government spending. Journal of Public Economics, 55(1), 121-140.

[21] Olofsgård, A. (2004). Secessions and political extremism: Why regional referenda do not solve the problem. Journal of the European Economic Association, 2(5), 805-832. 
[22] Persson, T., \& Svensson, L. E. (1989). Why a stubborn conservative would run a deficit: Policy with time-inconsistent preferences. The Quarterly Journal of Economics, 104 (2), 325-345.

[23] Radan, P. (2007). Creating new states. A. Pavkoviåc (Ed.). Ashgate Publishing.

[24] Ruta, M. (2005). Economic theories of political (dis) integration. Journal of Economic Surveys, 19(1), 1-21.

[25] Tabellini, G., \& Alesina, A. (1990). Voting on the Budget Deficit. The American Economic Review, 80(1), 37-49. 